\title{
The Research Convergence of Critical Infrastructures, Quality of Life and Safety
}

\author{
Liudmila V. Massel ${ }^{1,2}$ \\ ${ }^{1}$ Melentiev Energy Systems Institute of Siberian Branch of the Russian Academy of Sciences, \\ Lermontov str., 130 \\ Irkutsk, Russia \\ ${ }^{2}$ Irkutsk National Research Technical University, \\ Lermontov str., 83 \\ Irkutsk, Russia \\ E-mail:massel@isem.irk.ru
}

\begin{abstract}
The article discusses the possibility and necessity of research convergence of critical infrastructure, quality of life and safety. It is proposed to use the indicator of quality of life as one of the factors that must be considered when determining the critical facilities of critical infrastructure, and to include the degree of availability of energy in the required volume and quality required as one of the quality of life indicators. It's considered the possibilities of application in the research of critical infrastructures of the 3D-geovizualization tools developed by leadership of author. The use of the cognitive modelling methods is illustrated, developed by the author leadership to support decision-making in research and ensuring energy security for the integral index of quality of life. The examples of the developed models are shown.
\end{abstract}

Keywords: Critical infrastructures, quality of life, social security, cognitive modeling.

\section{Introduction}

The research team headed by the author ${ }^{1}$ has advanced in creating the instrumental tools to explore life quality, energy and cyber security. The analysis of research of critical infrastructures at the international level points out, that the methods developed by the team in this field correspond to this level. It appears, it is vital to integrate research of critical infrastructures, life quality and security. The life quality might become the factor to be considered in locating truly important objects of critical infrastructures as the objects of life support. In addition, it is proposed to expand the number of indicators of life quality with the indicator responsible for the rate of providing the population with energy resources of sufficient amount and required quality. When considering life quality and cyber security combined, it makes sense to allow for both vivid and implicit cyber threats indirectly affecting life quality. The paper illustrates application of the methods of cognitive modeling designed under the author's guidance to support decisionmaking in the studies and ensuring the energy security, to obtain the integral indicator of life quality. It is

\footnotetext{
${ }^{1}$ Departament of Information Technologies in Power Engineering of MESI SB RAS
}

reasonable to apply critical infrastructures of scientific visualization based on the author's instrumental tools of 3D-geovisualization. The paper offers examples of available cognitive models of life quality.

\section{Critical infrastructures}

In the case of military actions, one of the most vital targets to destruct would be the civil infrastructure, for its malfunction or demolition causes damages comparable to hitting military forces. The critical infrastructure is part of civil infrastructure being a combination of physical or virtual systems and means vital for a state to such an extent that when failed or destructed there might arise the disastrous consequences in the fields of defense, economics, public health and nation security [1]. The hierarchy structure includes eleven sectors in accordance with their significance set in «The National Strategy for the Physical Protection of Critical Infrastructure and Key Assets» of year 2003. The low and base level contain sectors: information-telecommunication, energy and water supply. Our research team performs studies in the two named fields [2]. In the USA, they currently distinguish 18 sectors of critical infrastructure, as indicated in the official site of the government [3]. 
The investigation and analysis of critical infrastructure are still at the initial stage of performance. This issue became a matter of concern only in the end of the past century. Thus, in July 1996 upon the Decree of the USA President № 13010 «On operations to investigate vulnerability of protection critical infrastructure from cyber and physical threats» they organized President's Commission on Critical Infrastructure Protection (PCCIP). Now the critical infrastructure studies are prioritized in many countries worldwide, primarily in the USA, where the level of information technology development and potential of modern complexes of imitation modelling is progressively increasing [1]. Amongst the scientific goals is protection of national critical infrastructure and organization of affecting its objects by an enemy. The main objective is establishing the key objects (or their combination), with the action on them causing the most negative effect onto the branch of economy, key resource or entire infrastructure, as well as evaluation of such impact and development of mechanisms of reducing risks. Such works are being performed at the Melentiev Energy Systems Institute of SB RAS (Irkutsk, Russia) as was represented by the author in [4].

Altogether, one of the difficulties in recognizing the key objects of critical infrastructure has been lack of a proper mathematic device. This limitation does not let us formulate quantitative indices of object vulnerability. This evidence points out that such investigations were based on the method of expert evaluations, which envisages obligatory presence of information on the possible damage or loss of «reference object » or elaboration of special scale of their risk («unsafety»).

The main disadvantage of such models is that they disregard linkage between the objects involved in critical infrastructure. Besides, it is problematic to ensure the adequacy of the object to the study model without analysis of network component of each sector of critical infrastructure (economic, financial and energetic).

In the USA, to eliminate these limitations, they launched formation of the cluster of research organizations dealing with designing mathematical models to investigate critical infrastructure.

Particular attention is given to the analysis of possible emergencies in the energy sector. In September 2003 the Ministry of Energy in the USA established the Visualization and Modeling Working Group (VMWG). It is to raise potential of the Ministry for a quick and comprehensive analysis of possible emergencies in the energy sector. The group employs the most advanced technologies, geoinformation systems, and the database of accidents at the objects of energy sector [1].

\section{Relationships between critically important objects}

To illustrate complexity of relationships between elements of critical infrastructures and importance to understand them, it is sensible to look upon the accident. It occurred on July 19, 2001, when the train of 62 cisterns transporting dangerous chemicals, came down from rails in the tunnel in Howard Street in Baltimore, the USA. Beside damage of railway and automobile communication, there occurred a cascade destruction of infrastructure: water supply system, the system of electricity distribution and telecommunications. Above that, the damage of rail track had consequences for the states New Jersey, Pennsylvania, Delaware, New York and Maryland, as the coal and steel transportation was delayed.

An accident of May 25, 2005 in the energy system of Moscow might exemplify complexity of relationships between critical infrastructures. The technogenous accident took place at power station № 510 «Chagino», located in the southeast of Moscow in the district Kapotnya, and as a result, 2 million people suffered from the accident. The direct causes of accident could be wear on equipment, absence of reserve capacities and high temperature retained in Moscow for many days (over 30 $\left.{ }^{\circ} \mathrm{C}\right)$. The «capital blackout» resulted in severe consequences: electric energy was disconnected in several districts of Moscow, Podmoscovie, Tula, Kaluga and Ryazan regions. Some tens of thousands of people were blocked in the trains of Moscow Metro and lifts, the railway communication and work of numerous commercial and governmental organization was disordered. The enterprises of Moscow, Podmoskovie and neighboring areas discharged sewage waters. The total loss of blackout estimated in Moscow reached 1.708 billion rubles, and in Moscow region, this figure reached 503.94 billion rubles [5].

Thus, the critical infrastructure of any state is a greatcomplicated system of strategic importance; it represents a combination of plentiful components of different types united by relations of diverse nature and sharing a common feature (affiliation, function) distinguished from the features of individual components of the whole set that requires development of special research methods.

\section{The methods to research critical infrastructure}

Principal approaches used in the study of critical infrastructures [1] are: theory of center of gravity by Clausewitz [6], similar method by Warden [7], theory of scale-free network by A. Barabasi [8]. In particular, the author's team have been conducting the works based on the use of complex network theory [9]. Application of 3D-geovisualization is illustrated in Figures1-2; they are analogous to those described in international publications. 


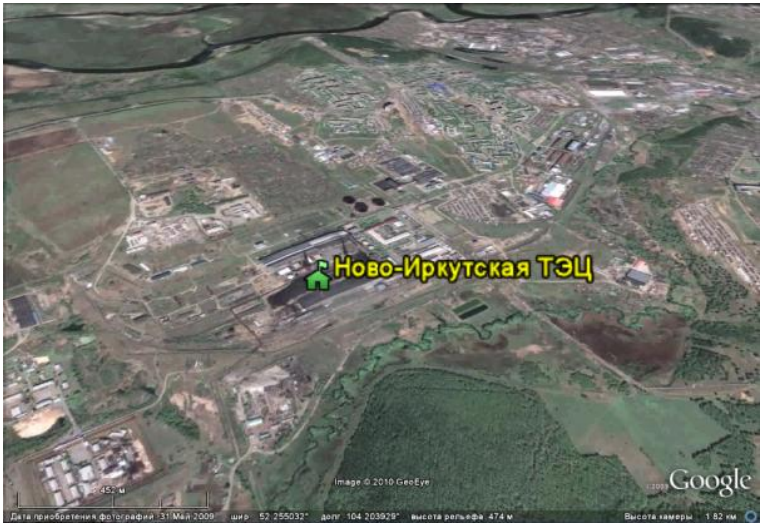

Fig. 1. Novo-Irkutsk Heat-and-Power Plant.

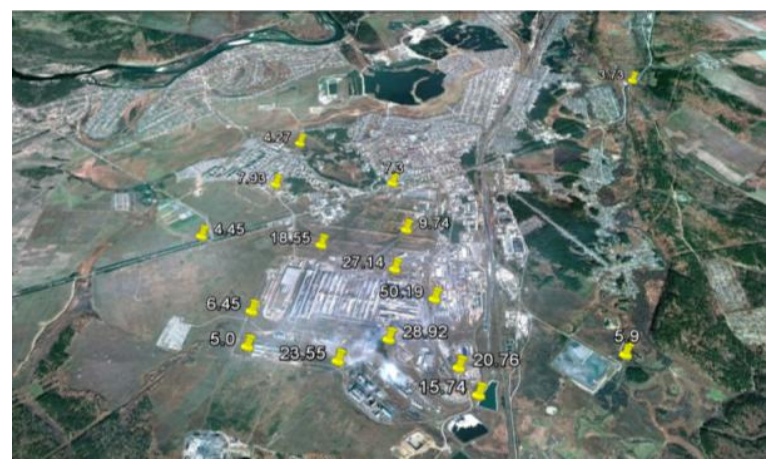

Fig. 2. Representation of the field of $\mathrm{SO}_{4}$ emissions into atmosphere close to Heat-and-Power Plant (Shelekhov town, Irkutsk Region).

The methods of semantic modeling will be reported below.

From the author's viewpoint, the study of critical infrastructure should be accomplished with due regard to the life concerns of population, which can be reflected in the indicator of life quality.

\section{Quality of life}

Foreign researchers first introduced the category «quality of life» in 1960s due to the initial modeling of industrial development trajectory. There are many definitions of life quality, but it was most fully disclosed in terms of health protection. According to World Health Organization, the life quality is perception by individuals their position in life in the context of culture and the system of values, in which they live, in accord with their objectives, expectations, norms and care.

The quality of life is understood as a set of subjective and objective parameters featuring the maximum number of man's sides, his position in society and satisfaction with it. Figure 3 provides the scheme of life quality components, as was defined by International Organization on Health Protection [10]. It is evident from the figure that quality of life is determined not only by financial welfare, but also it should consider the degree protectability, health, position in society, and most importantly, personal evaluation of these factors. The index of life quality summarizes the indicators of health, social-and-personal welfare and well-being.

Our research group performs the work, which substantiates the fact that acquisition of the integral index with strict mathematical method is complicated. We proposed to attract the methods of artificial intelligence, i.e. cognitive modeling being a trend of semantic modeling [11]. It is noteworthy, the integral index of life quality [12] does not include the effect of energy resource provisions, although their deficit might affect essentially both the level and quality of life. It makes sense to include the external factors, in particular the rate of energy resource provisions into the indicators of life quality [13].

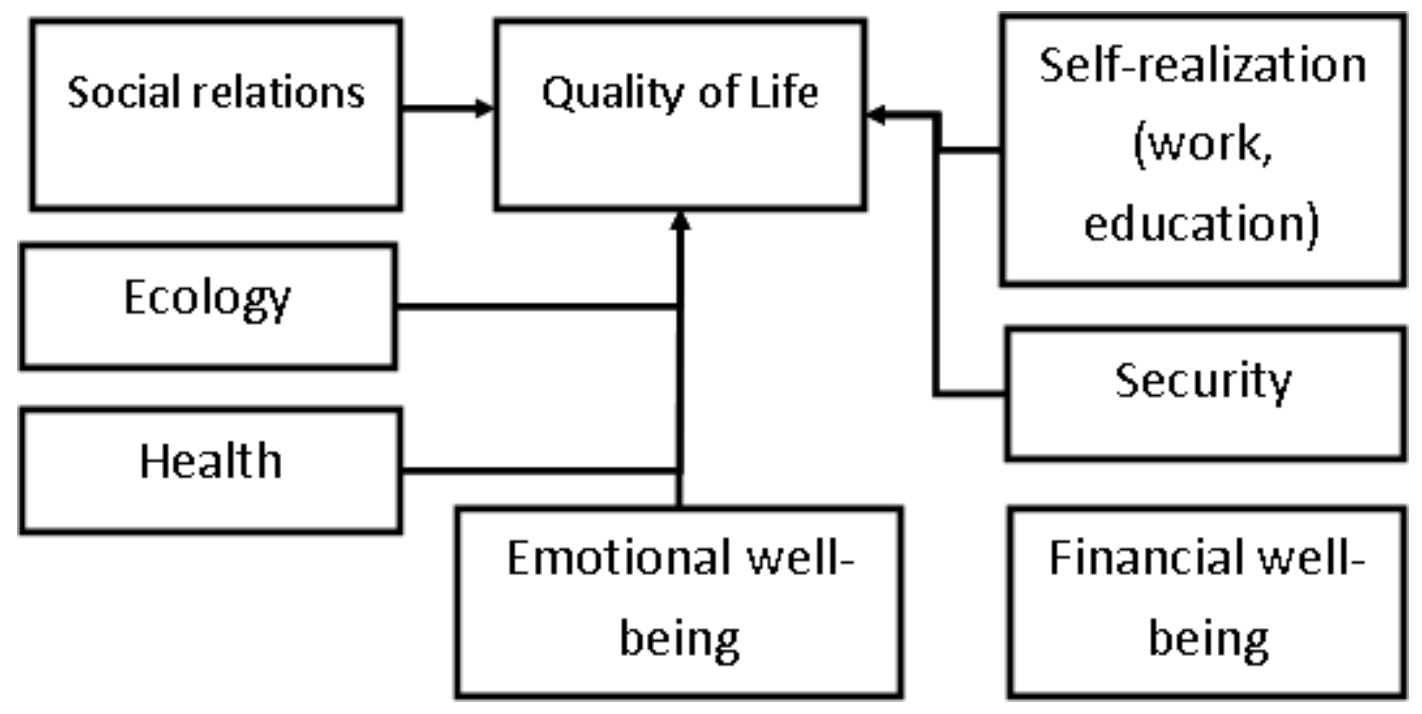

Fig. 3. Quality of life as defined by World Health Organization 
Semantic modeling represents a modern trend of artificial intelligence, and it is linked with description of the subject area with the concepts (base definitions) and relationships between them. Our group develops some types of semantic modeling like ontological, cognitive, event- triggering and probabilistic [14].

Ontological modeling is used for classification of subject area concepts. Cognitive modeling distinguishes relations between the concepts (factors) and contribution of factors, e.g. to formation of threats of energy security. Cognitive modeling implies building cognitive models or cognitive maps (oriented graphs), in which the peaks correspond to the factors (concepts), and the arc to the relations between factors (positive or negative), depending on the character of cause-and-effect relation. The relation is positive, if the increase (decrease) of one concept causes the increase (decrease) of the other. If the increase of the concept, on the contrary, causes decrease of the other, the relation is negative. The mathematical device for building cognitive models is theory of graphs.

R. Axelrod first proposed cognitive maps, as the method of investigation in 1976 for modeling, situation analysis and decision-making in the situations with high degree of uncertainty [15]. So-called «classic» cognitive map by Axelrod is interested for us, because the map includes both the factors involved in the indicator of life quality, and the factors related to energy resource provisions

Figure 4 displays the cognitive map of life quality indicators according to accepted procedure SF-36 [12] (all relations are positive). The main concepts of the cognitive map correspond to the indicators of the quality of life in SF-36 procedure [11, 13].

Designations in Figure 5:

- $\quad$ PF (Physical Functioning) - physical functioning.

- RP (Role-Physical Functioning) - role functioning conditioned by physical state.

- BP (Bodily pain) - pain intensity.

- $\mathrm{GH}$ (General Health) - general health.

- VT (Vitality) - life activity.

- SF (Social Functioning) - social functioning.

- RE (Role-Emotional) - role functioning preconditioned by emotional state.

- MH (Mental health) - Mental health.

- PHC (Physical health) - general component of physical health.

- MHC (Mental health) - general component of mental health.

- QoL (Quality of Life) - integral indicator of quality of life.

- COЭp (DSEr) - degree of supply with energy resources.

After processing (link analysis, removal of intermediaries (PHC and $\mathrm{MHC}$ ) and introduction of weighting factors), the cognitive map acquires the form shown in Fig. 6. The designations are the same as in
Figure 4. The proposed cognitive maps were applied in the studies of the quality of life in East-Siberian Institute of Medical and Environmental Research (Angarsk, Irkutsk region) [11].

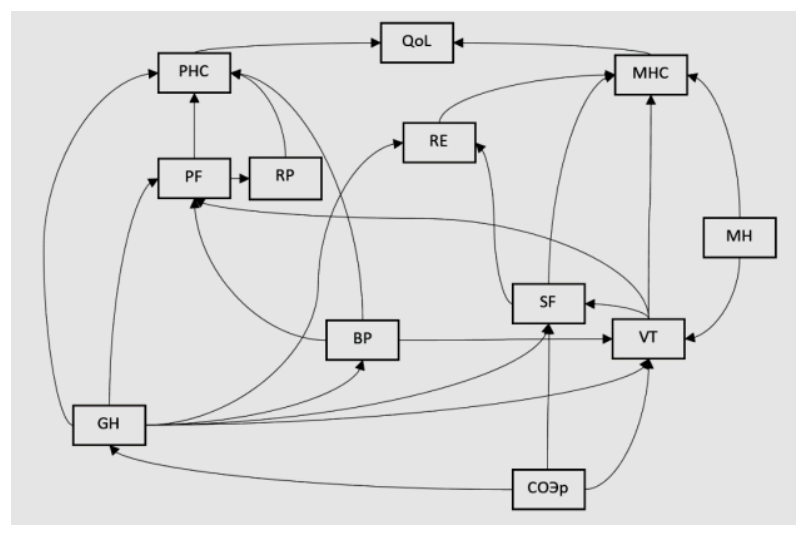

Fig. 4. Cognitive map of indicators of life quality using procedure SF-36 (all links are positive).

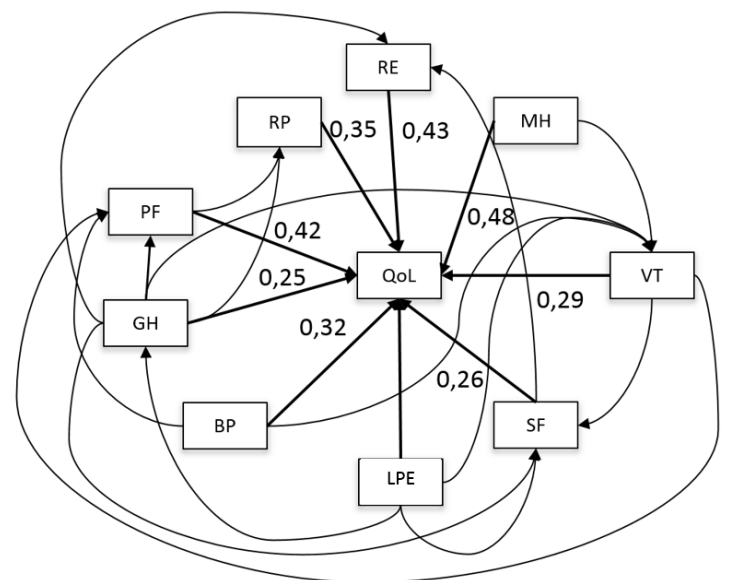

Fig. 5. Cognitive map of the structure of life quality following procedure SF-36 after processing (all links + ).

The studies accomplished verified possibility to employ cognitive modeling for obtaining an integral indicator of life quality using semantic modeling, as well as the reasoning to include an additional indicator of providing with energy resources.

In the structure of life quality, the definition «Safety» (Fig. 1) should be specified.

\section{Social security as an integral condition of quality of life}

Many specialists regard the definition of social security as fairly broad and multi-planned one [16]. Ignoring a comprehensive approach, our team consider only those kinds of threats, which are vital for common people in a general sense. The next types of threats have been recognized:

- Terroristic;

- Criminal;

- Insufficiency of water supply (pure water); 
- Deficit of foodstuff (ecologically pure products);

- Environmental pollution;

- Energetic security;

- Cybernetic security.

The population currently being under media pressing is concerned with the first two types, although following three are more dangerous, but probably their constant presence is habit-forming. Without dwelling upon this spectrum of threat, let us consider the last two, i.e. the threat to the energy and cyber security. They represent the issues of research, in which the author's team is involved.

Energetic security is understood as the rate of protectability of population, society, state, economics of deficit threat fuel and energy resources under normal conditions and in extreme situations, as well as from violation of stability, regularity of supplies with fuel and energy [17]. The extreme situations in energy are emergency and critical situations, their definitions based on the evaluation of system and object state with the scale: «norm», «pre-crisis» - critical situation, «crisis»emergency situation. With these in mind, the critical situations are those when threats arise for a regular functioning of technical objects, and the objects of life maintenance and/or the threat to life or health of individual people and social (professional) groups. These threats may be eliminated by undertaking preventive and operational measures, which do not allow a critical situation to overgrow into extreme one. It follows that to evaluate such situations it is necessary to analyze and rank such objects to distinguish critical ones. Formerly, the strategic threats to energy security did not include the cyber threat. However recently it was included into the list [18].

Cyber security, following standard T-REC-X.1205ITU-T is interpreted as a set of tools, strategies, leading principles of security, safety guarantee, approaches to governing risks, actions, professional training, practical experience, insurance and technologies, which may be used by the cyber environment, resources of organization and user.

Cyber environment means connected computer facilities, personnel, infrastructure, applications, services, telecommunication systems, as well as combination of transferred and/or stored information. Cyber safety consists in the effort to achieve and preserve the properties of safety of the organization or user resources directed against the threats to safety in the cyber environment. In our case cyber safety is interpreted according to standard ISO 27032:2012 as the one based on five components, however not being the synonym of neither of them. Of greatest concern in terms of critical infrastructures is protection of information in the key systems of information infrastructure being an integral part of critical infrastructures.
In addition to the evident ones, there are implicit cyber threats related to the sociological problems, which may significantly affect life quality:

- Influence on eyesight and health of man;

- Computer addiction and Internet-addiction;

- Numeric inequality;

- Computer crimes;

- Social threat (poor adaptability in the community of computer-addicted people; causing suicide in social networks);

- Computer games and virtual reality.

\section{Conclusion}

(1) It is reasonable to use the indicator «life quality» to define truly important objects in critical infrastructures; (2) It is necessary to pay greater attention to the threats to energy security and cyber security in exploring safety, as one of components of life quality;.(3) It is sensible to include the external indicator as the rate of providing energy resources; (4) It is appropriate to apply the methods of artificial intelligence to obtain the integral indicator of life quality, in particular methods of cognitive modeling.

These factors necessitate the interpenetration of the studies on critical infrastructures, quality of life and security, with particular stress on the energetic and cyber safety.

\section{Acknowledgments}

The results provided in the article have been acquired under the partial financial support of RFBR grants № 1607-00474, № 16-07-00569, № 18-57-81001. 


\section{References}

1. Modern trends in the study of critical infrastructure in foreign countries. http://pentagonus.ru/publ/soremnnye tendencii_v_issledvanii_kriticeskoj_infrastruktury_v_zarub ezhnoj_stranakh_2012/19-1-0-2082 (in Russian)

2. Massel' L. V., Massel' A. G., Development of intelligent semiotic systems for strategic situational management in critical infrastructures (using the example of energy sector, in Proceedings of the V International Scientific Conference "Information Technologies and Systems" IT\&S -2016. (Cheljabinsk: ChelGU). pp. 119-125. ISBN 978-5-72711343-1. (in Russian)

3. https://www.dhs.gov/critical-infrastructure-sectors

4. Edelev A. V., Senderov S. M., Sidorov I. A., Application of distributed computing to identify critical objects of the Russian gas transmission network, Information and mathematical technologies in science and management. Science Journal. №1 (2016) 55-62. ISSN 2413-0133. (in Russian).

5. http://www.eprussia.ru/epr/264/975889.htm

6. Clausewitz K., About the War. (Eksmo, Midgard, 2007) (in Russian).

7. Warden, J. Centers of gravity in military operations. Preliminary draft (Royal Swedish Defence College , 2004).

8. Albert R., Barabasi A.-L. 2002, Statistical mechanics of complex networks, Rev. Mod. Phys. 74, 47; arXiv:condmat/0106096.

9. Tihomirov A. A, Trufanov A. I., Nosyreva L. L., Nosyreva E. V. Mathematical description of stem networks, in Proceedings of the 17th Baikal All-Russian Conference "Information and mathematical technologies in science and management». (Irkutsk, 2012) Vol. 3 pp.149-153. (in Russian).

10. Health Impact Assessment Toolkit (World Health Organization, 2005).

11. Massel' L. V., Blohin A. A., Cognitive modeling of quality of life indicators: the proposed approach and an example of use, Bulletin of NSU. Series: Information technologies. Vol.14. №2. (2016) pp. 72-79 (in Russian).

12. Ajvazjan S. A., Integral indicators of the population quality of life: their construction and use in socio-economic management and interregional comparisons. (Moscow: CEMI RAS, 2000). (in Russian).

13. Massel' L. V., Blohin A. A., Cognitive modeling method of quality of life indicators taking into account external factors, Science and education. Scientific publication of the Bauman MSTU. №4. (2016) pp. 65-75. DOI: 10.7463/0416.0839061 (in Russian).

14. Massel' L. V., Massel' A. G., Semantic technologies based on the integration of ontological, cognitive and event modelling, in Proceedings III International Scientific and Technical Conference OSTIS-2013 (Belarussian. Minsk. BSUIR. 2013) pp. 247-250. (in Russian).

15. Axelrod R. The Structure of Decision: Cognitive Maps of Political Elites (Princeton: University Press, 1976).

16. Vorob'ev Ju. L., Akimov V. A., Sokolov Ju. I. Complex human security: Tutorial; Russian Emergency Situations Ministry (Moscow: FGU VNII GOCHS (FC), 2011). (in Russian).

17. Energy Security of Russia // V. V. Bushuev, N. I. Voropaj, A. M. Mastepanov, Ju. K. Shafranik i dr. (Novosibirsk: Science. Sib. Ed. Company of RAS, 1998). (in Russian).
18. Massel' L. V., Voropaj N. I., Senderov S. M., Massel' A. G., Cyber Danger as one of the Strategic Threats to Russia's Energy Security, Cybersecurity issues. 4(17) (2016) 2-10. (in Russian). 